\title{
Type 2 diabetes and its correlates among adults in Bangladesh: a population based study
}

\author{
Muhammad Abdul Baker Chowdhury ${ }^{1 *}$, Md Jamal Uddin², Hafiz M. R. Khan ${ }^{3}$ and Md Rabiul Haque ${ }^{4}$
}

\begin{abstract}
Background: Type 2 diabetes is one of the most prevalent non-communicable diseases in Bangladesh. However, the correlates of type 2 diabetes among adults in Bangladesh remain unknown. We aimed to investigate the correlates of type 2 diabetes among the adults in Bangladesh.

Methods: We conducted a cross-sectional study using data from the nationally representative 2011 Bangladesh Demographic and Health Survey. A random sample of 7,543 (3,823 women and 3,720 men) adults of age 35 years and older from both urban and rural areas, who participated in the survey was included. Diabetes was defined as having a fasting plasma blood glucose level of $\geq 7 \mathrm{~mm} / \mathrm{L}$ or taking diabetes medication during the survey. Hypothesized factors, e.g., age, sex, education, place of residence, social status, body mass index, and hypertension were considered in the analyses. Multivariable logistic regression models were used to identify the important correlates of type 2 diabetes.
\end{abstract}

Results: Among the respondents, the overall prevalence of diabetes was $11 \%$, and the prevalence was slightly higher in women (11.2\%) than men (10.6\%). Respondents with the age group of 55-59 years had higher odds of having diabetes (odds ratios $(\mathrm{OR})=2.37,95 \%$ confidence interval $(\mathrm{Cl})$ : $1.76-3.21$ ) than the age group of 35-39 years. Moreover, respondents who had higher educational attainment ( $\mathrm{OR}=1.67,95 \% \mathrm{Cl}: 1.18-2.36$ ) and higher social status ( $\mathrm{OR}=2.01,95 \% \mathrm{Cl}: 1.50-2.70)$ had higher odds of having diabetes than the respondents with no education and lower social status, respectively. We also found socioeconomic status, place of residence (rural or urban), regions of residence (different divisions), overweight and obesity, and hypertension as significant correlates of type 2 diabetes in Bangladesh.

Conclusions: Our study shows that older age, higher socioeconomic status, higher educational attainment, hypertension, and obesity were found to be significant correlates of type 2 diabetes. Need-based policy program strategies including early diagnosis, awareness via mass media, and health education programs for changing lifestyles should be initiated for older age, wealthy, and/or higher educated individuals in Bangladesh. Moreover, area-specific longitudinal research is necessary to find out the underlying causes of regional variations.

Keywords: Type 2 diabetes, Correlates, Population based study, BDHS, Bangladesh

\section{Background}

Diabetes is one of the most prevalent and serious noncommunicable diseases (NCDs) all over the world. It is the leading cause of death, disability, and economic loss, and, thus, it is identified as a major threat to global development [1-4]. Moreover, it can lead to a multitude of complications, such as heart disease, stroke, renal failure,

\footnotetext{
* Correspondence: mchow023@fiu.edu

'Department of Biostatistics, Robert Stempel College of Public Health \& Social Work, Florida International University, 11200 SW 8th Street, Miami, FL 33199, USA

Full list of author information is available at the end of the article
}

and blindness [5-7]. Therefore, it possesses a major health care burden all over the world [8]. Similar to the developed countries, several studies [3, 9-13] suggested that people of Asia, especially South East-Asia (SEA) are at a higher risk of type 2 diabetes irrespective of region, diet, and socioeconomic status [14]. According to the International Diabetes Federation (IDF) [3], the SEA region consisting of Bangladesh, India, Sri Lanka, and Nepal is the home of more than 72 million adults with diabetes, which is expected to exceed 135 million by $2035[3,15,16]$. Among the adults (age 20-79 years) 
with diabetes in the top five SEA countries, Bangladesh is in the second position [3]. The number of people with diabetes in Bangladesh was 5.10 million in 2013, which is expected to increase to 8.20 million (13\% of the total adults) by 2035 [3, 17]. A systematic review and meta-analysis between 1995 and 2010 showed that the prevalence of diabetes among the adults in Bangladesh has increased significantly, $4 \%$ in 19952000, $5 \%$ in 2001-2005, and $9 \%$ in 2006-2010 [12]. Although diabetes is a silent killer, nearly half of the population with diabetes is undiagnosed. Furthermore, among those diagnosed with diabetes, only 1 in 3 patients is treated and roughly 1 in 13 achieve treatment targets [18].

Several studies on diabetes have been conducted in Bangladesh [10, 19-22]. However, these studies were small-scale, confined to urban - rural communities or some other specific groups (e.g., slum residents), which did not demonstrate the wide range of correlates of diabetes for the whole country. Therefore, the objective of this study was to identify the correlates of type 2 diabetes using data from the 2011 Bangladesh Demographic and Health Survey (BDHS).

\section{Methods}

\section{The survey and data source}

The Demographic Health Survey (DHS) was designed to collect data to monitor and evaluate population, health, and nutrition status of developing countries [23]. In Bangladesh, this survey has been carried out continuously in a three year interval since 1993 under the authority of the National Institute for Population Research and Training (NIPORT) of the Ministry of Health and Family Welfare. The data files were released in the MEASURE DHS website [23], which are free and available for research. The survey followed the MEASURE DHS model questionnaire and was adopted for use in Bangladesh after a series of meetings with local and international experts [24]. The ICF International located in Calverton, Maryland provided the technical assistance, and the financial support was provided by the United States Agency for International Development (USAID) [24]. Each sequential series of this crosssectional survey is a nationally representative sample of non-institutionalized population. In this study, we used the data that was collected in 2011, which is the latest available data of the BDHS.

\section{Sampling design and sample size}

The 2011 BDHS used two-stage stratified cluster sampling from non-institutionalized individual households [24]. The sampling frame used for the survey was the complete list of enumeration areas (EA) covering the whole country of the most recent population census prepared by the Bangladesh Bureau of Statistics (BBS) [25]. An EA is a geographic area covering on average 113 households [24]. In the first stage, 600 EAs (207 urban, 393 rural) were selected with probability proportional to the EA size. In the second stage of sampling, a systematic sample of 30 households on average was selected from each sampling unit to provide statistically reliable estimates of key demographic and health variables for the country as a whole, for urban and rural areas separately, and for each of the seven divisions of Bangladesh. With this design, the survey selected 17,964 (11,754 rural, 6,210 urban) residential households. Among the selected households, 17,141 were interviewed successfully with a response rate of $98 \%$ [24]. For measuring biomarker information, a random subsample (one-third of the households) was selected. In this subsample, all women and men of ages 35 years and older were eligible to participate in the biomarker component, which included blood pressure measurements, testing for anemia, blood glucose testing, and height and weight measurements. A total of $8,835(4,524$ men and 4,311 women) household members of ages 35 years and older from 83,731 household members was included in the subsample [24]. Among them, $92 \%$ of women and $86 \%$ of men participated in the blood pressure measurement, and $89 \%$ of women and $83 \%$ of men participated in the blood glucose measurement [24]. After excluding the missing data and non-responses, the final sample size became 7,543. The sample design and sample selection process is presented in Fig. 1. The detailed survey procedure, study method, and questionnaires are available in the final report of 2011 BDHS [24].

\section{Study variables}

Information on socioeconomic and demographic characteristics of the respondents were collected including age, sex, education, marital status, working status, division of residence, place of residence (rural or urban), wealth status, and anthropomorphic characteristics like blood glucose level, blood pressure, history of diabetes and hypertension, and medication. Some indicators were determined through the physical examination. Height and weight were measured to calculate body mass index (BMI). The BMI was categorized into two categories: normal $(B M I \leq 24.99)$, overweight and obese (BMI $\geq 25$ ). Blood pressure and blood glucose were measured by trained health technicians [24].

\section{Measurements and diagnostic criteria for disease}

HemoCue 201+ blood glucose analyzer was used to measure the blood glucose [24]. The survey used the World Health Organization (WHO) [26] cut-off 


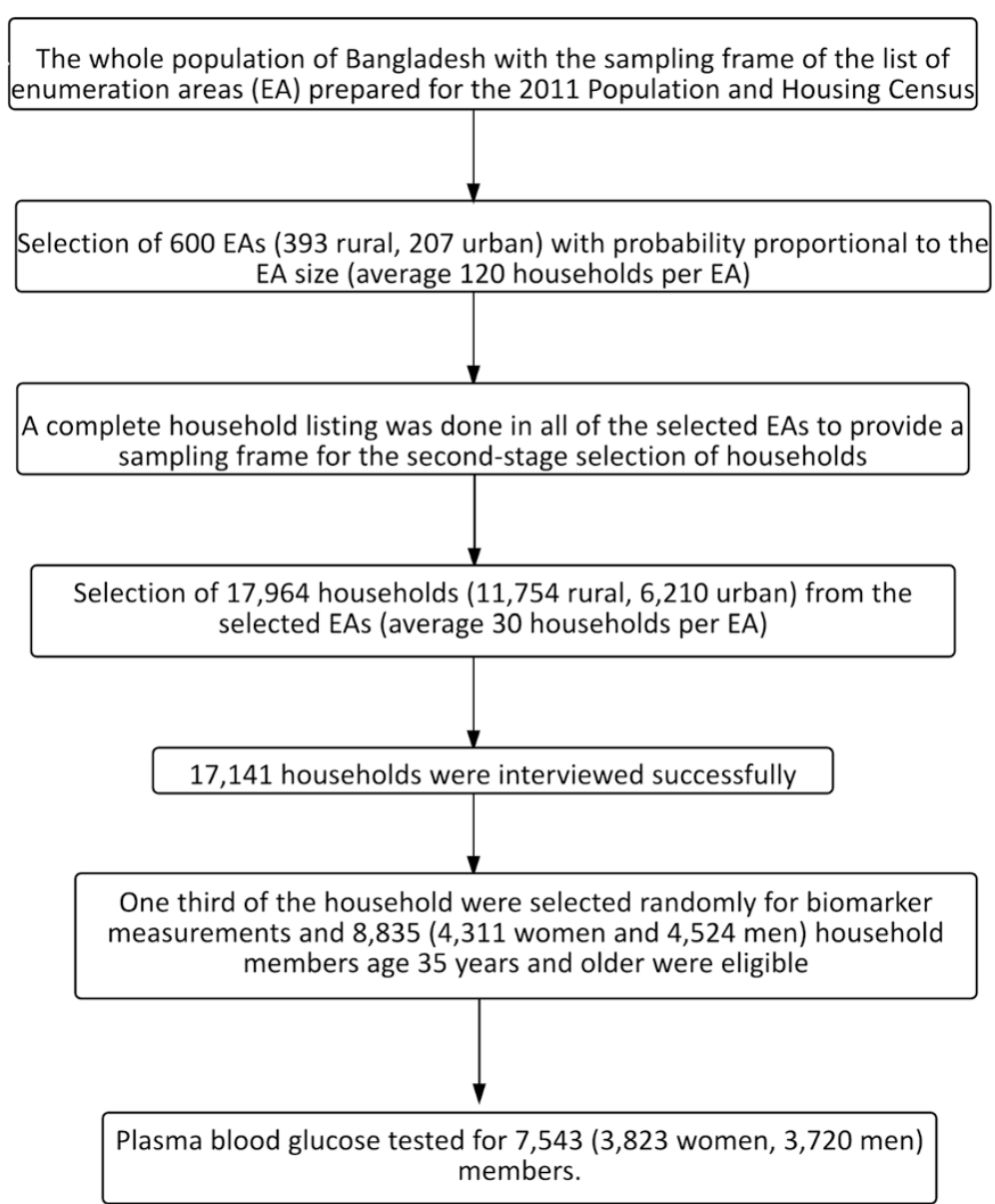

Fig. 1 Study population and sample selection

points for measuring fasting plasma blood glucose. An individual was defined as 'diabetic', if fasting plasma glucose level was $\geq 7.0 \mathrm{mmol} / \mathrm{L}$ or taking medication to reduce the blood sugar, 'pre-diabetic' if fasting plasma glucose level was $6.0-6.9 \mathrm{mmol} / \mathrm{L}$, and 'diabetes free' if fasting plasma glucose was below $6.0 \mathrm{mmol} / \mathrm{L}$ [26]. For our analysis, we merged two groups ('pre-diabetic' and 'diabetes free') together to make the variable dichotomous (diabetic patient and non-diabetic patient). The 2011 BDHS used the American Heart Association (AHA) [27] guidelines for cut-off points for blood pressure measurements. An individual was considered as hypertensive if systolic blood pressure (SBP) $\geq 140 \mathrm{mmHG}$ and/or diastolic blood pressure (DBP) $\geq 90 \mathrm{mmHG}$ and/or taking anti-hypertensive medication to reduce blood pressure. Pre-hypertension was defined by SBP $\geq 120 \mathrm{mmHg}$ but $<140 \mathrm{mmHg}$ and/ or DBP $\geq 80 \mathrm{mmHg}$ but $<90 \mathrm{mmHg}$ and/ or no anti-hypertensive medication at the time of survey. Individuals with $\mathrm{SBP}$ and $\mathrm{DBP} \leq 120 / 80$ were considered as normal [27].

\section{Statistical analysis}

We conducted bivariate analysis to compare the diabetic respondents across the categories for each of our study variables. A chi-square test was performed to determine the proportional differences by diabetes status. The correlates of diabetes among the adults were assessed by using multivariable logistic regression models. Odds ratios (OR) with $95 \%$ confidence intervals $(\mathrm{CI})$ for correlates of diabetes were estimated. The first model included all selected sociodemographic and economic characteristics, the second model included anthropometric characteristics, the third and the fourth model included interaction terms and square term of age, respectively, and the final model included significant predictors $(p<0.05)$ based on all four models. For selecting the best model, the value of $-2 \mathrm{LogLikelihood} \mathrm{ratio} \mathrm{test,} \mathrm{AIC,} \mathrm{and} \mathrm{the} \mathrm{area}$ under the receiver operating characteristic (ROC) curve was examined. The lower values of -2Log Likelihood ratio test and lower AIC value represent the better model. The area under the ROC curve 
measures the accuracy of the model. The summary of modelling exercise is presented in the Appendix (Table 5). An area of 1.0 represents the perfect test and an area of 0.5 represents the worthless test. Appropriate sample weights were used for the whole data set provided by the 2011 BDHS. We used SPSS 20.0 (SPSS, Inc) to analyze the data [28].

\section{Results}

A summary of the socioeconomic, demographic, and anthropometric characteristics of the diabetic and nondiabetic respondents was shown in Table 1. Among the respondents $(n=7,543), 49.3 \%$ were male and $50.7 \%$ were female. Respondents with older age and higher education had higher percentages of having diabetes compared to the respondents with a younger age and no education. It was also found that most of the diabetic respondents came from the richest households (39.1\%), followed by richer households (21.4\%), and the other wealth index categories had a similar proportion of diabetes (around $13 \%$ ). The correlates of diabetes differ significantly with the change in BMI and hypertension. Diabetes was more likely to occur among the study participants with higher body weights $(p<0.01)$. Twenty six percent of the diabetic respondents were overweight and obese, and about $65 \%$ of the hypertensive respondents had diabetes. Women and men of ages 35 years and older were asked questions related to any previous diagnosis of diabetes and whether they were taking medication to treat their diabetes. Figure 2 shows the awareness and treatment status of diabetes by sex and by place of residence. The awareness and treatment status among males were more or less similar in both rural and urban areas. However, females in the rural areas were less aware, and a lower proportion of them were taking medicine to control diabetes. Table 2 shows the method of medication of the diabetic patients. Seventy five percent of those receiving treatment take medication orally, $17.39 \%$ take injections, and $7.60 \%$ take medication both orally and by injection. Table 3 shows the distribution of education, body mass index, and hypertension status by place of residence. The urban respondents were found to have higher BMI (26.9 \% vs $5.4 \%)$ and be more hypertensive (62.7\% vs $50.2 \%$ ) compared to the rural respondents. Table 4 shows the odds ratios and confidence intervals from multivariable logistic regression analysis for different correlates of type 2 diabetes. Participants with increased age and having higher education, higher socioeconomic status, hypertension, and higher BMI were more likely to have type 2 diabetes. Individuals aged 55-59 years had more than two times the chance $(\mathrm{OR}=2.37,95 \% \mathrm{CI}: 1.76-3.21)$ of having diabetes than the individuals aged 35-39 years old. In addition, respondents with higher education were 1.67 (95\% CI: 1.18-2.36) times more likely to have diabetes compared to the respondents with no education. The analysis also indicated that individuals who were employed were less prone $(\mathrm{OR}=0.74,95 \% \mathrm{CI}: 0.58-0.95)$ to have diabetes compared to those who were not engaged with any work. The wealthier respondents were twice as likely $(\mathrm{OR}=2.01,95 \% \mathrm{CI}: 1.50-2.70)$ to be diabetic compared to the lowest income group (reference group) of the population. The odds of having diabetes between overweight and obese persons was found to be 1.83 (95 \% CI: 1.51-2.23) compared to the normal weight respondents, and the result was highly statistically significant. Individuals having hypertension were 1.41 (95 \% CI: 1.19-1.66) times more likely to have diabetes than the individuals who does not have hypertension. Neither sex nor marital status was strongly associated with having diabetes. A wide variation in the correlates of diabetes was found among the respondents of seven administrative divisions of Bangladesh. Study participants from Barisal, Chittagong, and Dhaka divisions had higher odds of having diabetes compared to the study participants from the Sylhet division.

\section{Discussion}

Our study shows that older age, higher education, affluent socioeconomic status, hypertension, and obesity are significant correlates of type 2 diabetes among the adult population in Bangladesh. We found that respondents between ages 55-59 years have a higher odds of having diabetes compared to those ages 35-39 years. Due to the decline in fertility level and a steady increase in life expectancy in Bangladesh, the population age structure is changing. The number of old age population will increase rapidly, which will strengthen the correlates of diabetes among older age population in the near future. Moreover, diabetes occurs much more among the respondents with higher educational attainment and higher social status. These findings are found to be consistent with previous studies conducted in Bangladesh [10, 22, 29-32] and some neighboring countries $[11,33]$. Furthermore, the degree and extent of correlates of type 2 diabetes varies by level of socioeconomic status and income. For example, studies demonstrate that the higher socioeconomic status plays a major role in the reduction of diabetes in the developed countries [34-36], whereas in Bangladesh, we found an inverse relation between higher educational attainment and having diabetes. This result is in line with the other studies of developing countries [34], especially in Asia [37, 38]. We also found that individuals having a higher educational attainment were more likely to have type 2 
Table 1 Socioeconomic, demographic, and anthropometric characteristic of the study participants by diabetes status, Bangladesh Demographic and Health Survey (BDHS), 2011

\begin{tabular}{|c|c|c|c|c|c|c|c|}
\hline \multirow[b]{2}{*}{ Variables } & \multicolumn{2}{|l|}{ Total } & \multicolumn{2}{|c|}{ Non diabetic } & \multicolumn{2}{|c|}{ Diabetic } & \multirow[t]{2}{*}{$p$-value } \\
\hline & $n$ & $\%$ & $n$ & $\%$ & $n$ & $\%$ & \\
\hline Age group & & & & & & & $<0.001$ \\
\hline $35-39$ & 1415 & 18.8 & 1295 & 19.3 & 120 & 14.5 & \\
\hline $40-44$ & 1320 & 17.5 & 1196 & 17.8 & 124 & 15.0 & \\
\hline $45-49$ & 1167 & 15.5 & 1037 & 15.4 & 130 & 15.7 & \\
\hline $50-54$ & 1013 & 13.4 & 907 & 13.5 & 106 & 12.8 & \\
\hline $55-59$ & 668 & 8.9 & 554 & 8.2 & 114 & 13.8 & \\
\hline $60-69$ & 1057 & 14.0 & 928 & 13.8 & 129 & 15.6 & \\
\hline $70+$ & 904 & 12.0 & 799 & 11.9 & 105 & 12.7 & \\
\hline Sex & & & & & & & 0.402 \\
\hline Male & 3720 & 49.3 & 3324 & 49.5 & 396 & 47.9 & \\
\hline Female & 3823 & 50.7 & 3393 & 50.5 & 430 & 52.1 & \\
\hline Marital status & & & & & & & 0.159 \\
\hline Currently married & 6355 & 84.3 & 5673 & 84.5 & 682 & 82.6 & \\
\hline Others (divorced/separated/widowed) & 1188 & 15.7 & 1044 & 15.5 & 144 & 17.4 & \\
\hline Education level & & & & & & & $<0.001$ \\
\hline No education & 3581 & 47.5 & 3282 & 48.9 & 299 & 36.2 & \\
\hline Primary education & 2459 & 32.6 & 2164 & 32.2 & 295 & 35.7 & \\
\hline Secondary education & 1066 & 14.1 & 909 & 13.5 & 157 & 19.0 & \\
\hline Higher education & 437 & 5.8 & 362 & 5.4 & 75 & 9.1 & \\
\hline Working status & & & & & & & 0.001 \\
\hline Not currently working & 3933 & 52.2 & 3456 & 51.5 & 477 & 57.7 & \\
\hline Currently working & 3607 & 47.8 & 3257 & 48.5 & 350 & 42.3 & \\
\hline Wealth index & & & & & & & $<0.001$ \\
\hline Poorest & 1472 & 19.5 & 1365 & 20.3 & 107 & 12.9 & \\
\hline Poorer & 1438 & 19.1 & 1332 & 19.8 & 106 & 12.8 & \\
\hline Middle & 1493 & 19.8 & 1379 & 20.5 & 114 & 13.8 & \\
\hline Richer & 1561 & 20.7 & 1384 & 20.6 & 177 & 21.4 & \\
\hline Richest & 1579 & 20.9 & 1256 & 18.7 & 323 & 39.1 & \\
\hline Place of residence & & & & & & & $<0.001$ \\
\hline Urban & 1761 & 23.3 & 1478 & 22.0 & 283 & 34.2 & \\
\hline Rural & 5782 & 76.7 & 5238 & 78.0 & 544 & 65.8 & \\
\hline Division of residence & & & & & & & $<0.001$ \\
\hline Sylhet (Eastern) & 429 & 5.7 & 378 & 5.6 & 51 & 6.2 & \\
\hline Chittagong (Southeastern) & 1256 & 16.7 & 1077 & 16.0 & 179 & 21.6 & \\
\hline Dhaka (Central) & 2457 & 32.6 & 2180 & 32.5 & 277 & 33.5 & \\
\hline Khulna (Western) & 992 & 13.2 & 920 & 13.7 & 72 & 8.7 & \\
\hline Rajshahi(Mid-western) & 1082 & 14.3 & 966 & 14.4 & 116 & 14.0 & \\
\hline Rangpur(Northwestern & 898 & 11.9 & 820 & 12.2 & 78 & 9.4 & \\
\hline Barisal (Southern) & 428 & 5.7 & 374 & 5.6 & 54 & 6.5 & \\
\hline
\end{tabular}


Table 1 Socioeconomic, demographic, and anthropometric characteristic of the study participants by diabetes status, Bangladesh Demographic and Health Survey (BDHS), 2011 (Continued)

\begin{tabular}{lllllll}
\hline Body mass index & & & & & \\
Normal & 6321 & 86.5 & 5732 & 88.1 & 589 & 73.6 \\
$\quad$ Overweight/ obese & 985 & 13.5 & 774 & 11.9 & 211 & 26.4 \\
Hypertension & & & & & & $<0.001$ \\
No & 3533 & 46.8 & 3243 & 48.3 & 290 & 35.1 \\
Yes & 4010 & 53.2 & 3474 & 51.7 & 536 & 64.9 \\
\hline
\end{tabular}
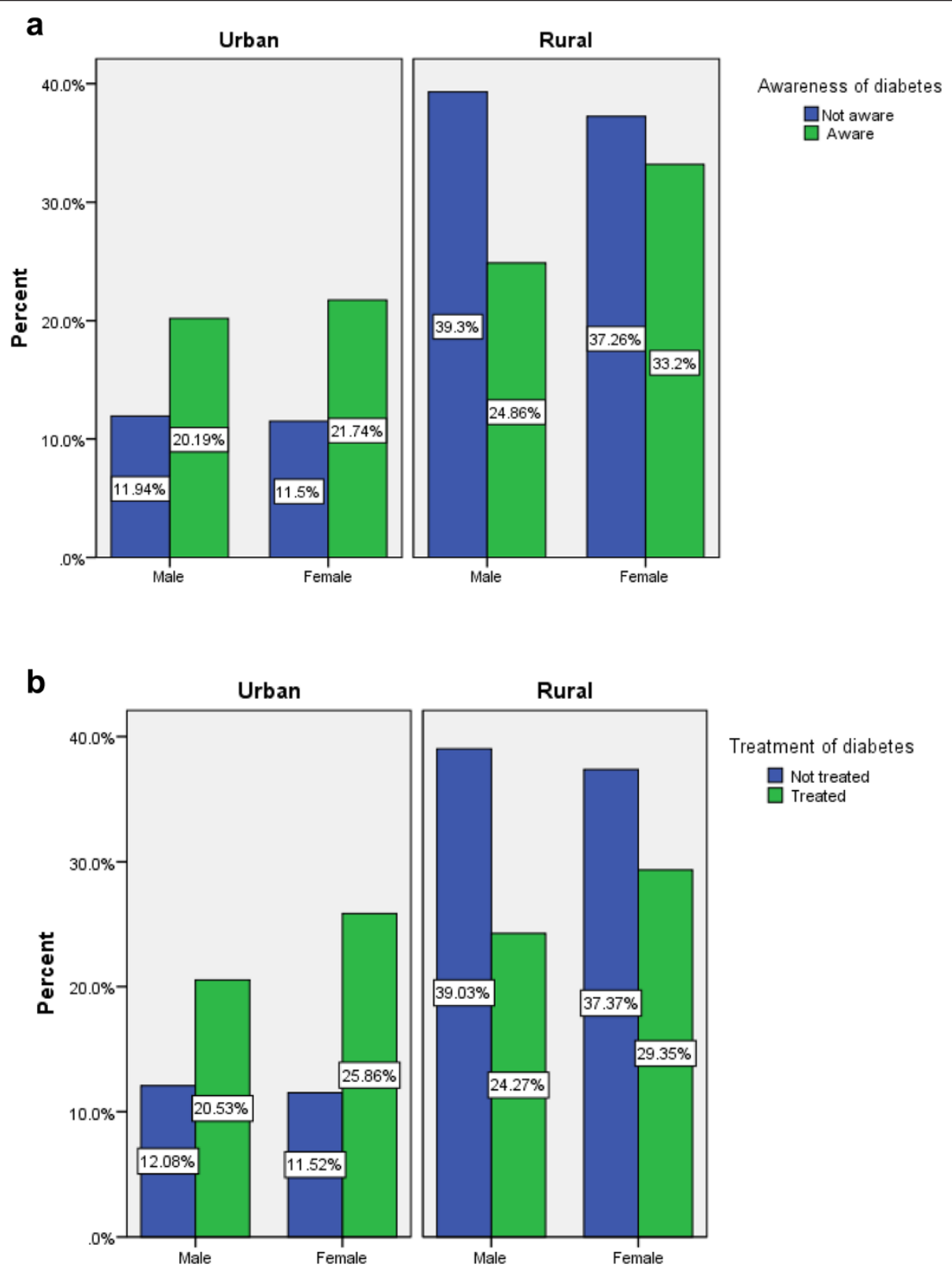

Treatment of diabetes

$\square$ Not treated

Treated

Fig. 2 Awareness and treatment status of diabetes by sex and place of residence, Bangladesh Demographic and Health Survey (BDHS), 2011. a Awareness of diabetes $\mathbf{b}$ Treatment of diabetes 
Table 2 Method of medication of diabetes patients by sex, Bangladesh Demographic and Health Survey (BDHS), 2011

\begin{tabular}{|c|c|c|c|c|c|c|}
\hline \multirow[b]{2}{*}{ Medication type } & \multicolumn{2}{|c|}{ Male } & \multicolumn{2}{|c|}{ Female } & \multicolumn{2}{|c|}{ Total } \\
\hline & $n$ & $\%$ & $n$ & $\%$ & $n$ & $\%$ \\
\hline Injected & 22 & 17.9 & 26 & 17.0 & 48 & 17.4 \\
\hline Orally & 95 & 77.2 & 112 & 73.2 & 207 & 75.0 \\
\hline Injected and orally & 6 & 4.9 & 15 & 9.8 & 21 & 7.6 \\
\hline
\end{tabular}

diabetes compared to less educated individuals. Similar findings were also observed in studies conducted in Bangladesh [29, 30], China [11, 39], and India [33]. Individuals living in urban areas are more likely to have higher BMI and higher odds of having diabetes compared to the individuals residing in rural areas. For example, the overweight or obese individuals are 1.83 times more likely to have diabetes compared to normal weight individuals. Similar findings were found in a study among secretariat employees of Bangladesh [21]. Rahim et al. [10] and Sayed et al. [30] also found that weight gain is a significant predictor of type 2 diabetes among Bangladeshi populations. In contrast, studies conducted by Hussain et al. found a minor correlation between type 2 diabetes and higher BMI for both men and women in 2005 [20] and 2007 [20, 40]. Hence, our study, as well as several previous studies, confirmed that being overweight and obese is the independent and strongest correlate of type 2 diabetes, irrespective of gender, race, and region [32, 41-47]. Several authors showed that for one unit of increase in BMI there is a possibility of increase of diabetes by $12 \%$ [43]. Educated

Table 3 Distribution of education, BMI, and hypertension by place of residence, Bangladesh Demographic and Health Survey (BDHS), 2011

\begin{tabular}{|c|c|c|c|c|c|c|c|}
\hline \multirow[b]{2}{*}{ Variables } & \multicolumn{2}{|l|}{ Total } & \multicolumn{2}{|c|}{ Urban } & \multicolumn{2}{|l|}{ Rural } & \multirow[t]{2}{*}{$p$-value } \\
\hline & $n$ & $\%$ & $n$ & $\%$ & $n$ & $\%$ & \\
\hline Education level & & & & & & & $<0.001$ \\
\hline No education & 3582 & 47.5 & 584 & 33.2 & 2998 & 51.8 & \\
\hline Primary education & 2458 & 32.6 & 562 & 31.9 & 1896 & 32.8 & \\
\hline Secondary education & 1067 & 14.1 & 381 & 21.6 & 686 & 11.9 & \\
\hline Higher education & 436 & 5.8 & 233 & 13.2 & 203 & 3.5 & \\
\hline Body mass index & & & & & & & $<0.001$ \\
\hline Normal & 6322 & 86.5 & 1,252 & 73.1 & 5070 & 90.6 & \\
\hline Overweight/ obese & 985 & 13.5 & 460 & 26.9 & 525 & 5.4 & \\
\hline Hypertension & & & & & & & $<0.001$ \\
\hline No & 3533 & 46.8 & 656 & 37.3 & 2877 & 49.8 & \\
\hline Yes & 4010 & 52.2 & 1105 & 62.7 & 2905 & 50.2 & \\
\hline
\end{tabular}

and wealthy individuals may be used to living in urban areas, consuming more fast food, and fatty foods, as well as participating less in physical exercise, which may be the important causes of being overweight and obese, prolonging the correlate of diabetes [48]. The rural people are more likely to be engaged in daily household and other labor intensive activities, and burn a lot of calories that may keep them physically active and lead to lower BMI. Moreover, urban people have insufficient facilities to have physical exercise and to maintain a healthy life which leads them to have higher BMI and therefore, more likely to have diabetes in low and middle income countries [40].

Type 2 diabetes was found to be associated with hypertension. This finding is consistent with cross sectional studies in Bangladesh [21, 22, 40], India [49], China [39], Taiwan [50], and Nigeria [51]. Two population based studies also found that untreated high blood pressure has been linked to diabetes [52]. However, some studies also found the coexistence of hypertension and diabetes [53, 54] across different ethnic, racial, and social groups.

The correlates of diabetes also varied by the regions of residence in Bangladesh: adults from Barisal (Southern), Chittagong (Southeastern), and Dhaka (Central) divisions were more likely to have diabetes compared to the respondents from Sylhet (Eastern) division. There may be limited facilities of physical activity available in these divisions, and individuals are unwilling to take those advantages due to huge road traffic and public safety issues. Since the reasons for these variations are still unknown, longitudinal cohort studies may be conducted to examine the underlying causes behind this variation among the divisions of Bangladesh.

\section{Strength and limitations}

Our study provides evidence of the correlates of type 2 diabetes using the nationally representative sample with comprehensive information on diabetes as well as associated demographic and anthropomorphic characteristics. To our knowledge, this is the first survey in Bangladesh, which collected information on diabetes for adult population by using WHO recommended methods. Therefore, the findings are more representative compared to the previous small scale studies in the country. Despite these strengths, there are several limitations to our study. The findings are generalizable only for the adult populations in developing countries. Apart from the correlates of type 2 diabetes mentioned here, there are a significant number of factors, such as insulin resistance, race or ethnic background, family history of diabetes $[30,55]$, dieting habits, life 
Table 4 Estimates of odds ratios and confidence intervals of different correlates of diabetes, Bangladesh Demographic and Health Survey (BDHS), 2011

\begin{tabular}{|c|c|c|}
\hline Variables & OR & $95 \% \mathrm{Cl}$ \\
\hline \multicolumn{3}{|l|}{ Age group } \\
\hline $35-39$ & 1.00 & \\
\hline $40-44$ & 1.12 & $(0.85-1.47)$ \\
\hline $45-49$ & 1.36 & $(1.03-1.79)^{* *}$ \\
\hline $50-54$ & 1.36 & $(1.02-1.82)^{* *}$ \\
\hline $55-59$ & 2.37 & $(1.76-3.21)^{* * *}$ \\
\hline $60-69$ & 1.74 & $(1.29-2.35)^{* * *}$ \\
\hline $70+$ & 1.56 & $(1.10-2.20)^{* *}$ \\
\hline \multicolumn{3}{|l|}{ Sex } \\
\hline Male & 1.00 & \\
\hline Female & 0.83 & $(0.65-1.08)$ \\
\hline \multicolumn{3}{|l|}{ Marital status } \\
\hline Currently married & 1.00 & \\
\hline Others (divorced/separated/widowed) & 1.08 & $(0.85-1.37)$ \\
\hline \multicolumn{3}{|l|}{ Education level } \\
\hline No education & 1.00 & \\
\hline Primary education & 1.32 & $(1.09-1.60)^{* *}$ \\
\hline Secondary education & 1.49 & $(1.15-1.93)^{* *}$ \\
\hline Higher education & 1.67 & $(1.18-2.36)^{* *}$ \\
\hline \multicolumn{3}{|l|}{ Working status } \\
\hline Not currently working & 1.00 & \\
\hline Currently working & 0.74 & $(0.58-0.95)^{* *}$ \\
\hline \multicolumn{3}{|l|}{ Wealth index } \\
\hline Poorest & 1.00 & \\
\hline Poorer & 0.88 & $(0.66-1.17)$ \\
\hline Middle & 0.86 & $(0.65-1.15)$ \\
\hline Richer & 1.19 & $(0.90-1.57)$ \\
\hline Richest & 2.01 & $(1.50-2.70)^{* * *}$ \\
\hline \multicolumn{3}{|l|}{ Place of residence } \\
\hline Urban & 1.00 & \\
\hline Rural & 0.98 & $(0.82-1.22)$ \\
\hline \multicolumn{3}{|l|}{ Division of residence } \\
\hline Sylhet (Eastern) & 1.00 & \\
\hline Barisal (Southern) & 1.90 & $(1.51-2.37)^{* *}$ \\
\hline Chittagong (Southeastern) & 1.63 & $(1.31-1.97)^{* * *}$ \\
\hline Dhaka (Central) & 1.42 & $(1.04-1.94)^{* *}$ \\
\hline Khulna (Western) & 0.54 & $(0.36-0.80)$ \\
\hline Rajshahi (Mid-western) & 1.04 & $(0.70-1.47)$ \\
\hline Rangpur(Northwestern) & 0.80 & $(0.54-1.19)$ \\
\hline \multicolumn{3}{|l|}{ Body Mass Index } \\
\hline Normal & 1.00 & \\
\hline Overweight/ obese & 1.83 & $(1.51-2.23)^{* * *}$ \\
\hline
\end{tabular}

Table 4 Estimates of odds ratios and confidence intervals of different correlates of diabetes, Bangladesh Demographic and Health Survey (BDHS), 2011 (Continued)

Hypertension

\begin{tabular}{lll} 
No & 1.00 \\
Yes & 1.41 & $(1.19-1.66)^{* * *}$ \\
\hline Notes: ${ }^{* * *} p$ value $<0.001,{ }^{* *} p$ value $<0.05$ &
\end{tabular}

style, physical activity, cholesterol level, and cigarette smoking etc., which may be associated with diabetes $[39,56]$. We could not include these factors because they were not available in the 2011 BDHS data. Future work should be considered addressing these factors in Bangladesh.

\section{Conclusions}

Consistent with the literature, we found that there is a wide range of factors, which are significantly correlated with type 2 diabetes among the adults in Bangladesh. The findings demonstrate that individuals with older age, higher socioeconomic status, higher education, high BMI, and hypertension have a significant influence on the odds of having diabetes. Moreover, a significant proportion of the adult men and women are not aware of the consequence of this disease, and a small proportion of them are taking medication to control their blood sugar. Since diabetes is a modifiable disease, several recommendations and policy implications can be made based on our study findings. Country-wide diabetes screening programs could be implemented for early diagnosis and control of diabetes with special attention to the older age individuals. These screening programs may help to reduce long-term health complications and the financial cost for the care of the disease. We found that educated and wealthy individuals are more likely to have diabetes in our study. Therefore, motivational programs (i.e., adopting a healthy lifestyle, changing dietary habits, managing blood pressure level, and reducing body weights) should be implemented through specific public health interventions for the wealthy and/or individuals with higher educational attainment. Finally, multi-sectoral preventive strategies including health education programs, especially incorporating information on correlates of type 2 diabetes in the text curriculum at secondary and higher secondary level to build awareness of the disease, mass media campaign to promote physical activity, healthy dieting, and lifestyle changing is essential in Bangladesh. 


\section{Appendix}

Table 5

\begin{tabular}{|c|c|c|c|c|c|}
\hline Models & Variables & -2 Log likelihood & AIC & $\begin{array}{l}\text { H-L Goodness-of-Fit } \\
\text { Test (Pr }>\text { ChiSq) }\end{array}$ & $\overline{A \cup C}(\mathrm{ROC})$ \\
\hline \multirow[t]{3}{*}{ Model 1} & \multirow{3}{*}{$\begin{array}{l}\text { Sociodemographic and economic } \\
\text { characteristics: age, sex, marital status, } \\
\text { education, working status, wealth quantile, } \\
\text { place of residence, region of residence }\end{array}$} & Intercept Only = 5213.292 & Intercept Only $=5215.292$ & \multirow[t]{3}{*}{0.1127} & \multirow[t]{3}{*}{0.67} \\
\hline & & Intercept and & Intercept and & & \\
\hline & & Covariates $=4926.142$ & Covariates $=4976.142$ & & \\
\hline \multirow[t]{3}{*}{ Model 2} & \multirow{3}{*}{$\begin{array}{l}\text { Anthropometric characteristics: } \\
\text { hypertension, body mass index }\end{array}$} & Intercept Only = 5051.305 & Intercept Only = 5053.305 & \multirow[t]{3}{*}{0.1692} & \multirow[t]{3}{*}{0.61} \\
\hline & & Intercept and & Intercept and & & \\
\hline & & Covariates $=4909.086$ & Covariates $=4915.086$ & & \\
\hline \multirow[t]{3}{*}{ Model 3} & \multirow{3}{*}{$\begin{array}{l}\text { Model with square of age : age square, sex, } \\
\text { marital status, education, working status, } \\
\text { wealth quantile hypertension, body mass } \\
\text { index, place of residence, region of } \\
\text { residence }\end{array}$} & Intercept Only = 5051.305 & Intercept Only $=5053.305$ & \multirow[t]{3}{*}{0.3319} & \multirow[t]{3}{*}{0.67} \\
\hline & & Intercept and & Intercept and & & \\
\hline & & Covariates $=4745.731$ & Covariates $=4789.731$ & & \\
\hline \multirow[t]{3}{*}{ Model 4} & \multirow{3}{*}{$\begin{array}{l}\text { Model with interaction terms age, sex, } \\
\text { marital status, education, working status, } \\
\text { wealth quantile hypertension, body mass } \\
\text { index, place of residence, region of } \\
\text { residence residence*education, } \\
\text { residence*BMl, residence*hypertension }\end{array}$} & Intercept Only = 5053.305 & Intercept Only $=5051.305$ & \multirow[t]{3}{*}{0.3691} & \multirow[t]{3}{*}{0.68} \\
\hline & & Intercept and & Intercept and & & \\
\hline & & Covariates $=4776.559$ & Covariates $=4712.559$ & & \\
\hline \multirow[t]{3}{*}{ Model 5} & \multirow{3}{*}{$\begin{array}{l}\text { Final model (Socio demographic, economic, } \\
\text { and anthropometric characteristics): age, sex, } \\
\text { marital status, education, working status, } \\
\text { wealth quantile hypertension, body mass } \\
\text { index, place of residence, region of } \\
\text { residence }\end{array}$} & Intercept Only = 5051.305 & Intercept Only = 5053.305 & \multirow[t]{3}{*}{0.3789} & \multirow[t]{3}{*}{0.68} \\
\hline & & Intercept and & Intercept and & & \\
\hline & & Covariates $=4713.467$ & Covariates $=4767.467$ & & \\
\hline
\end{tabular}

\section{Abbreviations}

AHA: American Heart Association; AUC: Area under the curve; BBS: Bangladesh Bureau of Statistics; BDHS: Bangladesh Demographic and Health Survey; BMI: Body mass index; Cl: Confidence interval; DHS: Demographic Health Survey; DBP: Diastolic blood pressure; IDF: International Diabetes Federation; NCD: Non-communicable diseases; NIPORT: National Institute for Population Research and Training; OR: Odds ratio; ROC: Receiver operating characteristic; SBP: Systolic blood pressure; SEA: South East-Asia; USAID: United States Agency for International Development; WHO: World Health Organization.

\section{Competing interests}

We have no competing interest.

\section{Authors' contributions}

MABC: Conceived the idea for the study, designed the research, analysis and interpretation of data, drafted the manuscript, revised it critically for important intellectual content, and final approval of the version to be submitted; MJU: Helped in statistical analysis and drafting manuscripts, revising it critically for important intellectual content, and final approval of the version to be submitted; HK: Revised the manuscript critically for important intellectual content, and final approval of the version to be submitted; MRH: Handled supervision of overall work, revised manuscript critically for important intellectual content and final approval of the version to be submitted. All authors read and approved the final manuscript.

\section{Acknowledgements}

We would like to thank MEASURE DHS and NIPORT for allowing us to use the data set. We also would like to thank faculty members of the Department of Population Sciences, University of Dhaka, Bangladesh for their inspiration, suggestion, and assistance in all aspects. We wish to thank Dr. Soulmaz Fazeli Farsani, Research Fellow, Division of Pharmacoepidemiology \& Clinical Pharmacology, Utrecht University, Nederland for her very helpful advice in revising the manuscript. We are thankful to Jeanette Garcia, Graduate Consultant, Writing
Center, Florida International University for her help in copy editing. We are also thankful to the editor and reviewers for their valuable comments and suggestion which led to significant improvements of the manuscript.

\section{Author details}

'Department of Biostatistics, Robert Stempel College of Public Health \& Social Work, Florida International University, 11200 SW 8th Street, Miami, FL 33199, USA. ${ }^{2}$ Department of Statistics, Shahjalal University of Science \& Technology, Sylhet 3114, Bangladesh. ${ }^{3}$ Department of Public Health, Texas Tech University Health Sciences Center, Lubbock, TX 79430, USA. ${ }^{4}$ Department of Population Sciences, University of Dhaka, Dhaka 1000, Bangladesh.

Received: 23 March 2015 Accepted: 12 October 2015

Published online: 19 October 2015

\section{References}

1. Lozano R, Naghavi M, Foreman K, Lim S, Shibuya K, Aboyans V, et al. Global and regional mortality from 235 causes of death for 20 age groups in 1990 and 2010: a systematic analysis for the Global Burden of Disease Study 2010. Lancet. 2012;380(9859):2095-128.

2. Murray CJL, Vos T, Lozano R, Naghavi M, Flaxman AD, Michaud C, et al. Disability-adjusted life years (DALYS) for 291 diseases and injuries in 21 regions, 1990-2010: a systematic analysis for the Global Burden of Disease Study 2010. Lancet. 2012;380(9859):2197-223.

3. International Diabetes Federation (IDF). Diabetes Atlas. 6th ed. Brussels: International Diabetes Federation; 2013.

4. Chen L, Magliano DJ, Zimmet PZ. The worldwide epidemiology of type 2 diabetes mellitus-present and future perspectives. Nat Rev Endocrinol. 2012;8(4):228-36.

5. Kumar SS, Houlden RL. Ethnocultural diversity and the diabetes epidemic in Canada: a call to action. Can J Diab. 2005;29(2):84-5. 
6. Oldroyd J, Banerjee M, Heald A, Cruickshank K. Diabetes and ethnic minorities. Postgrad Med J. 2005;81(958):486-90.

7. World Health Organization. World Health Statistics 2013 a wealth of information on global public health. 2013.

8. Ramachandran A, Wan Ma RC, Snehalatha C. Diabetes in Asia. Lancet. 2010;375(9712):408-18.

9. Shera AS, Rafique G, Khawaja IA, Baqai S, King H. Pakistan National Diabetes Survey: prevalence of glucose intolerance and associated factors in Baluchistan province. Diabetes Res Clin Pract. 1999;44(1):49-58.

10. Rahim MA, Hussain A, Azad Khan AK, Sayeed MA, Keramat Ali SM, Vaaler S. Rising prevalence of type 2 diabetes in rural Bangladesh: a population based study. Diabetes Res Clin Pract. 2007;77(2):300-5.

11. Yang W, Lu J, Weng J, Jia W, Ji L, Xiao J, et al. Prevalence of diabetes among men and women in China. N Engl J Med. 2010;362(12):1090-101.

12. Saquib N, Saquib J, Ahmed T, Khanam MA, Cullen MR. Cardiovascular diseases and type 2 diabetes in Bangladesh: a systematic review and meta-analysis of studies between 1995 and 2010. BMC Public Health. 2012;12(1):434.

13. Zhang $H, X u$ W, Dahl AK, Xu Z, Wang HX, Qi X. Relation of socio economic status to impaired fasting glucose and Type 2 diabetes: findings based on a large population based cross sectional study in Tianjin, China. Diabet Med. 2013;30(5):e157-62.

14. Balarajan R, Bulusu L, Adelstein AM, Shukla V. Patterns of mortality among migrants to England and Wales from the Indian subcontinent. Br Med J (Clin Res Ed). 1984;289(6453):1185-7.

15. Ramachandran A, Snehalatha C, Ma RCW. Diabetes in South-East Asia: an update for 2013 for the IDF Diabetes Atlas. Diabetes Res Clin Pract. 2014;103(2):231-7.

16. Ramachandran A, Mary S, Yamuna A, Murugesan N, Snehalatha C. High prevalence of diabetes and cardiovascular risk factors associated with urbanization in India. Diabetes Care. 2008;31(5):893-8.

17. Aguiree F, Brown A, Cho NH, Dahlquist G, Dodd S, Dunning T, et al. Diabetes Atlas. 6th ed. 2013.

18. Latif ZA, Jain A, Rahman MM. Evaluation of management, control, complications and psychosocial aspects of diabetics in Bangladesh: DiabCare Bangladesh 2008 Bangladesh Med Res Counc Bull. 2011;37(1):11-6.

19. Sayeed MA, Banu A, Khan AR, Hussain MZ. Prevalence of diabetes and hypertension in a rural population of Bangladesh. Diabetes Care. 1995; 18(4):555-8.

20. Hussain A, Rahim MA, Azad Khan AK, Ali SMK, Vaaler S. Type 2 diabetes in rural and urban population: diverse prevalence and associated risk factors in Bangladesh. Diabet Med. 2005;22(7):931-6.

21. Nazmul Ahasan HAM, Islam Z, Alam B, Miah T, Nur Z, Rabbi Mohammed F, et al. Prevalence and risk factors of type 2 diabetes mellitus among secretariat employees of Bangladesh. J Med. 2011;12(2):125.

22. Bhowmik B, Afsana F, Diep LM, Binte Munir S, Wright E, Mahmood S, et al. Increasing prevalence of type 2 diabetes in a rural Bangladeshi population: a population based study for 10 years. Diabetes Metab J. 2013;37(1):46-53.

23. MEASURE DHS. Demographic and Health Surveys [http://www.dhsprogram.com] [Accessed on December, 2014)

24. National Institute of Population Research and Training (NIPORT), Mitra and Associates, and ICF International. 2013. Bangladesh Demographic and Health Survey 2011. Dhaka, Bangladesh and Calverton, Maryland, USA: NIPORT, Mitra and Associates, and ICF International.

25. Bangladesh Bureau of Statistics. Bangladesh population and housing census 2011. Dhaka: Ministry of Planning Dhaka; 2012.

26. World Health Organization. Definition and diagnosis of diabetes mellitus and intermediate hyperglycaemia: Report of a WHO/IDF consultation. Geneva: World Health Organization; 2006.

27. American Heart Association. [http://www.heart.org/] [Accessed on December, 2014)

28. SPSS IBM. IBM SPSS statistics for Windows, version 20.0. New York: IBM Corp; 2011

29. Sayeed MA, Ali L, Hussain MZ, Rumi MA, Banu A, Khan AKA. Effect of socioeconomic risk factors on the difference in prevalence of diabetes between rural and urban populations in Bangladesh. Diabetes Care. 1997:20(4):551-5.

30. Sayeed MA, Mahtab H, Khanam PA, Latif ZA, Ali SMK, Banu A, et al. Diabetes and impaired fasting glycemia in a rural population of Bangladesh. Diabetes Care. 2003;26(4):1034-9.
31. Bhowmik B, Binte Munir S, Ara Hossain I, Siddiquee T, Diep LM, Mahmood S, et al. Prevalence of type 2 diabetes and impaired glucose regulation with associated cardiometabolic risk factors and depression in an urbanizing rural community in Bangladesh: a population-based cross-sectional study. Diabetes Metab J. 2012;36(6):422-32

32. Rahman MM, Rahim MA, Nahar Q. Prevalence and risk factors of type 2 diabetes in an urbanizing rural community of Bangladesh. Bangladesh Med Res Counc Bull. 2007:33(2):48-54.

33. Ramachandran A, Snehalatha C, Kapur A, Vijay V, Mohan V, Das AK, et al. High prevalence of diabetes and impaired glucose tolerance in India: National Urban Diabetes Survey. Diabetologia. 2001;44(9):1094-101.

34. Robbins JM, Vaccarino V, Zhang H, Kasl SV. Socioeconomic status and type 2 diabetes in African American and non-Hispanic white women and men: evidence from the Third National Health and Nutrition Examination Survey. Am J Public Health. 2001:91(1):76.

35. Robbins JM, Vaccarino V, Zhang H, Kasl SV. Excess type 2 diabetes in African-American women and men aged $40-74$ and socioeconomic status: evidence from the Third National Health and Nutrition Examination Survey. J Epidemiol Community Health. 2000;54(11):839-45.

36. Connolly V, Unwin N, Sherriff P, Bilous R, Kelly W. Diabetes prevalence and socioeconomic status: a population based study showing increased prevalence of type 2 diabetes mellitus in deprived areas. J Epidemiol Community Health. 2000:54(3):173-7.

37. World Health Organization G. Prevention of diabetes millatus report of a WHO study group. Geneva: WHO; 1994. p. 844.

38. Chan JCN, Malik V, Jia W, Kadowaki T, Yajnik CS, Yoon K-H, et al. Diabetes in Asia: epidemiology, risk factors, and pathophysiology. JAMA. 2009;301(20):2129-40.

39. Pan $X-R$, Yang $W-Y$, Li G-W, Liu J. Prevalence of diabetes and its risk factors in China, 1994. Diabetes Care. 1997;20(11):1664-9.

40. Hussain A, Vaaler S, Sayeed MA, Mahtab H, Ali SMK, Khan AKA. Type 2 diabetes and impaired fasting blood glucose in rural Bangladesh: a population-based study. Eur J Public Health. 2007;17(3):291-6.

41. Chan JM, Rimm EB, Colditz GA, Stampfer MJ, Willett WC. Obesity, fat distribution, and weight gain as risk factors for clinical diabetes in men. Diabetes Care. 1994;17(9):961-9.

42. Willett WC, Manson JE, Stampfer MJ, Colditz GA, Rosner B, Speizer FE, et al. Weight, weight change, and coronary heart disease in women: risk within the 'normal' weight range. JAMA. 1995;273(6):461-5.

43. Ford ES, Williamson DF, Liu S. Weight change and diabetes incidence: findings from a national cohort of US adults. Am J Epidemiol. 1997;146(3):214-22.

44. Wannamethee SG, Shaper AG. Weight change and duration of overweight and obesity in the incidence of type 2 diabetes. Diabetes Care. 1999:22(8):1266-72.

45. Yoon K-H, Lee J-H, Kim J-W, Cho JH, Choi Y-H, Ko S-H, et al. Epidemic obesity and type 2 diabetes in Asia. Lancet. 2006;368(9548):1681-8.

46. Khan MMH, Gruebner $\mathrm{O}$, Kraemer A. The geography of diabetes among the general adults aged 35 years and older in Bangladesh: recent evidence from a cross-sectional survey. PLoS One. 2014;9(10):e110756.

47. Dong Y, Gao W, Nan H, Yu H, Li F, Duan W, et al. Prevalence of type 2 diabetes in urban and rural Chinese populations in Qingdao, China. Diabet Med. 2005;22(10):1427-33.

48. Popkin BM, Adair LS, Ng SW. Global nutrition transition and the pandemic of obesity in developing countries. Nutr Rev. 2011;70(1):3-21.

49. Mohan V, Shanthirani CS, Deepa R. Glucose intolerance (diabetes and IGT) in a selected South Indian population with special reference to family history, obesity and lifestyle factors-the Chennai Urban Population Study (CUPS 14). J Assoc Physicians India. 2003:51:771-7.

50. Lu FH, Yang YC, Wu JS, Wu CH, Chang CJ. A population-based study of the prevalence and associated factors of diabetes mellitus in southern Taiwan. Diabet Med. 1998;15(7):564-72.

51. Olatunbosun ST, Ojo PO, Fineberg NS, Bella AF. Prevalence of diabetes mellitus and impaired glucose tolerance in a group of urban adults in Nigeria. J Natl Med Assoc. 1998;90(5):293.

52. Gress TW, Nieto FJ, Shahar E, Wofford MR, Brancati FL. Hypertension and antihypertensive therapy as risk factors for type 2 diabetes mellitus. N Engl J Med. 2000;342(13):905-12.

53. Mengesha AY. Hypertension and related risk factors in type 2 diabetes mellitus (DM) patients in Gaborone City Council (GCC) clinics, Gaborone, Botswana. Afr Health Sci. 2008;7(4):244

54. Lago RM, Singh PP, Nesto RW. Diabetes and hypertension. Nat Clin Pract End Met. 2007:3(10):667. 
55. Jayawardena R, Ranasinghe P, Byrne NM, Soares MJ, Katulanda P, Hills AP. Prevalence and trends of the diabetes epidemic in South Asia: a systematic review and meta-analysis. BMC Public Health. 2012;12(1):380.

56. Mokdad AH, Ford ES, Bowman BA, Dietz WH, Vinicor F, Bales VS, et al.

Prevalence of obesity, diabetes, and obesity-related health risk factors, 2001. JAMA. 2003;289(1):76-9.

Submit your next manuscript to BioMed Central and take full advantage of:

- Convenient online submission

- Thorough peer review

- No space constraints or color figure charges

- Immediate publication on acceptance

- Inclusion in PubMed, CAS, Scopus and Google Scholar

- Research which is freely available for redistribution 